\title{
A Materials Bank for Circular Leuven: How to Monitor 'Messy' Circular City Transition Projects
}

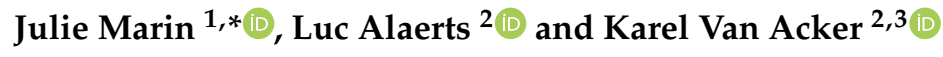 \\ 1 OSA Research Group Urbanism \& Architecture, Department of Architecture, KU Leuven, \\ Kasteelpark Arenberg 1, 3001 Leuven, Belgium \\ 2 Department of Materials Engineering, KU Leuven, Kasteelpark Arenberg 44, 3001 Leuven, Belgium; \\ luc.alaerts@kuleuven.be (L.A.); karel.vanacker@kuleuven.be (K.V.A.) \\ 3 Center for Economics and Corporate Sustainability (CEDON), KU Leuven, Warmoesberg 26, \\ 1000 Brussels, Belgium \\ * Correspondence: julie.marin@kuleuven.be
}

Received: 14 November 2020; Accepted: 3 December 2020; Published: 11 December 2020

check for updates

\begin{abstract}
In recent years, cities have revealed themselves as being prominent actors in the circular economy transition. Besides supporting and initiating urban projects catalyzing circularity, cities are looking for monitoring tools that can make their progress towards circularity visible. Adopting Leuven's pilot project for a building materials bank as a case study, this paper notes the particular challenges and opportunities in the pilot project to assess its progress and impact, in combination with gathering data for overall circular city monitoring purposes. Firstly, the paper names tensions between the "messy" transition process from policy ambitions to implementation and the question of data and monitoring. Secondly, the paper identifies relevant dimensions and scales to evaluate progress and impacts of a building materials bank, drawing from its development process. Thirdly, it proposes guidelines to monitor and evaluate circular city projects from the bottom up, combining quantitative indicators with guiding questions in a developmental evaluation. The analysis serves a critical reflection, distills lessons learned for projects contributing to circular cities and feeds a few concluding policy recommendations. The case study serves as an example that, in order to move beyond the tensions between circularity monitoring and actual circular city project development, monitoring instruments should simultaneously interact with and feed the circularity transition process. Therefore, dedicated data governance driven by enhanced stakeholder interactions should be inscribed in transition process guidance. Bottom-up projects such as a building materials bank provide opportunities to do this.
\end{abstract}

Keywords: circular city; transition; Leuven 2030; building materials bank; monitoring; wood flow analysis

\section{Introduction}

In the process of setting strategies and targets to make a transition to a sustainable world happen, the initial focus on the national level has in more recent years shifted towards cities, the latter finding themselves currently at the forefront of progressive action, with outspoken ambitions to become circular and/or climate neutral in the coming decades [1-5]. The size of transition challenges is very apparent in cities, as their territories account for only 2 percent of the total global land surface, but three quarters of all natural resources are consumed in cities, half of global waste is generated in cities and 60-80 percent of greenhouse gases are emitted from cities [6]. Additionally, cities account for 85 percent of the global GDP and are home to 54 percent of the world's population, projected to increase to almost $70 \%$ by 2050 [7]. Hence the material flows reaching very high concentrations within city territories compared 
to the hinterlands, together with the presence of large amounts of business actors and consumers, makes cities arenas where the driving forces of circular economy transitions may find high traction.

\subsection{Science: What Is A Circular City and How to Monitor Progress and Impacts?}

However, there is no consensus on what a circular economy, a circular urban project or circular city exactly entails [8-16]. A commonly adopted notion of circular economy is keeping materials and products performant at their highest application level as long as possible, while reducing environmental impacts and being aware of environmental trade-offs [17]. Nevertheless, circular economy (CE) has also been put forward as an alternative economic paradigm that stays within planetary boundaries and is socially just [18] or even post-growth [19]. In the context of cities, the core thinking behind circularity lies in the transition from linear to circular urban metabolisms. In his Gaia Atlas of Cities, Girardet [20] (p. 23) explains that a city with a linear metabolism takes its required resources from a hinterland without considering either as parts of natural ecosystems, thereby causing destruction of the natural environment. Contrarily, cities with circular metabolisms relate material inputs with outputs, using 'waste' as resource while taking into account impacts on places of extraction and disposal and limiting the material distances traveled. Girardet's emphasis on the interdependency between resource use and territorially anchored land-based natural ecosystems is reduced in later 'circularity' representations such as the Ellen MacArthur Foundation's 'butterfly scheme' [21], focusing on 'closing resource loops' after consumption so mainly intervening at the end of the extraction-production-consumption-disposal chain. Not taking into account the origin of the materials extracted to produce projects in the first place detaches the circular economy from its hinterland(s). In short, circular city projects are multiscalar; material objects or urban projects are interdependent with a multitude of hinterlands throughout the materials chain.

Furthermore, in concrete circular city projects or imaginaries, different overarching political agendas exist. The article 'Interpreting circularity' [22] explains that the self-claimed world's first zero waste circular city, Masdar City in Abu Dhabi, interprets circularity as referring to 'zero-waste', following industrial ecology principles to close and optimize resource loops. Masdar City is an entirely new city where architecture and urban design strategies create natural ventilation and shaded streets and state-of-the art technology maximally reuses water and produces clean energy. However, this 'circular city' does not take the occupation of a piece of desert into account, or the extraction of materials needed to realize this entirely new city. On the other hand of the circularity spectrum, the circular city project R-Urban near Paris redistributes common natural resources in local resource cycles within an existing community. In R-Urban, inhabitants capture and redistribute local resource flows such as rain water and locally produced food, making it accessible to everyone as part of the 'commons'.

Literature on circular cities indeed is increasingly moving beyond the conception of circular cities as zero-waste cities towards more comprehensive approaches covering multiple urban dimensions and overcoming both technological and organizational silos supporting regenerative urban systems [23,24]. Acknowledging circular cities' multidimensionality related to the culture of cooperation, synergies, and symbioses that are key to the self-sustainability of urban and territorial systems complicates assessments that go beyond the 'materials and energy' dimensions in the circular urban economy [25]. This is challenging, as involved stakeholders and (local) politicians often require reporting on progress and results, possibly against targets, in order for transition initiatives and projects to keep attracting their support. The famous quote ascribed to Peter Drucker, "What gets measured gets managed", even takes it a step further, stating that without indicators, no progress will be realized. Ideal indicators are able to evaluate progress and provide feedback, demonstrating effectiveness of actions and allowing the identification of factors of success and failure. Moreover, they allow us to visualize the results of the delivered efforts, and to benchmark performances among peer initiatives [26]. Ideally, monitoring takes place from macro to micro, covering the means (money, people) directly put in place to start the transition, the process (running activities and projects), the direct results and the indirect, broader effects, and both technological and socio-economic aspects, all in order to capture the full dynamics 
and impacts of a transition throughout its evolution $[27,28]$. To move beyond materials and energy cycles in circularity, Boeri et al. address governance, actions, actors, spaces, and resources and propose a combination of indicators for impacts that are policy-driven, innovation-driven, social-driven, and indicate the success of the process [23].

Natural as well as social sciences study the circular city transition. Adopting Korhonen's framework [9], the former essentially emphasize CE tools, metrics, instruments, and indicators and the latter deal with CE norms, values, world views, visions, and concepts. A key challenge in circular city research is to integrate these different approaches. However, circular city transition is a structurally complex 'wicked problem' [29] that has no clear solutions or goals to reach up until the moment they are achieved. It is unclear where they begin or stop and they might have multiple solutions or remain unresolved. To acknowledge the circular city transition's wicked nature, evaluations should be developmental instead of traditional [30,31] (p. 77). Developmental evaluations provide feedback, generate learnings and develop new monitoring mechanisms as goals emerge, and evolve to support ongoing learning. They capture system dynamics, interdependencies, models, and emergent interconnections and respond strategically to what is unfolding rather than aiming to control the process [30].

At present, there is no ready-to-use monitor dedicated to the progress of the circular economy in cities or city projects sufficiently covering the dimensions listed above. The state-of-the-art existing city-level indicators have been captured in two recent initiatives. Within the Urban Agenda initiative, an extended set of indicators has been compiled using the European Commission monitoring framework as a guideline, serving as a first version of a toolbox aimed to guide cities that want to experiment with indicators [32]. Within the CIRCTER (Circular Economy and Territorial Consequences) project, a more in-depth analysis of what indicators based on currently available data are covering and a gap analysis have been provided [33]. If a monitor was to be based only on indicators for which data are available today, it would have a rather narrow focus on waste and recycling, on circular employment based on a very limited definition, and on a mere counting and listing of running actions, while any causal link to results in terms of material consumption or to effects like a reduction of greenhouse gas emissions would be absent. This is evident for instance in indicator sets developed for Brussels, London, and Porto $[4,6,34]$.

In recent years, a number of promising conceptual frameworks has been developed in terms of amenability to the city level. In the region of Flanders, a CE monitor is being developed based on so-called systems to fulfill societal needs [17]. The provided connections between society-wide indicator scores and scores at the level of products and materials opens up the way towards a more direct policy feedback. At present, indicators for the mobility system are already available as part of a CE monitor [35]. This approach could be directly applied at the city level by narrowing down the underlying datasets to the city scale.

The model of the Doughnut Economy, an economy that stays within planetary boundaries and provides minimal social standards, has been recently tested at the city scale [24]. It displays four lenses that consider the local vs. the global level, and the effects on people vs. on the natural habitat. In the context of CE monitoring, the added value of the doughnut model is mainly highlighting the importance of indicators showing the broader and indirect effects of a CE transition. The city of Amsterdam started the 'Amsterdam Doughnut Coalition', connecting paradigm change agents that are developing a framework of necessary conditions that need to be met within the region in order to reach the doughnut goals. One of the defined 'conditions' is a doughnut dashboard enabling monitoring how Amsterdam is performing. Also, a CE monitor explicitly based on the doughnut framework has been developed [36]. The base structure of the monitor focuses on raw materials entering the system, waste leaving the system, and keeping products and materials in cycles, while also considering impacts. Apparently major efforts have been put into obtaining bottom-up data on material streams-in this way, tackling a major bottleneck at the city level. In its current version, this monitor did not lead yet to a substantial addition beyond the state-of-the-art indicator or data development, as it does not provide 
clear links yet between the data on material streams and the four lenses as available in the doughnut model, thereby hampering more direct policy feedback. The bottleneck might be that consumption of materials in itself is in fact neutral in the doughnut model—only the effects of consumption are visible in impacts like greenhouse gas emissions, land degradation, etc.

In conclusion, the key challenge is to develop a circular city monitor that incorporates multiple relevant geographical scales where materials originate, are processed, or end up as well as multiple transition dimensions beyond materials and energy, thereby supporting the circular city transition as a developmental process. This in part implies integrating components that are essentially not measurable in a quantitative way. The key challenges for developing a next generation of indicators or monitors are: 1. obtaining both overall and detailed data on material flows, as these are generally lacking at the city level, with a few exceptions [37]; 2. finding ways to correctly deal with spatial aspects (e.g., a focus on direct flows within a city versus indirect upstream and/or downstream flows taking place due to final demand or production in a city [38]; 3. providing more direct policy feedback [17]; 4. bringing together evidence to demonstrate causality between key results and indirect effects [28]; and 5. an accommodation of the diversity of cities and projects, in order to allow for cities or city projects to stand out with their particular progress and to equally reward progress in frontrunners vs. laggards [32].

\subsection{Policy: Transitioning Leuven to A Circular City}

This paper focuses on the city of Leuven, a relatively compact and mid-sized city with ca. 100,000 inhabitants located in Flanders, Belgium, at about $25 \mathrm{~km}$ east of the capital Brussels. The potential of cities as hotspots to accelerate sustainability transitions as described above already started to materialize in Leuven since 2013, with the installation of a public-private partnership named Leuven Klimaatneutraal, and renamed in 2016 as the non-profit organization Leuven 2030. The city government is a key contributor in this partnership, together with knowledge institutions, civil society organizations, sector organization, a number of large companies located in the city, and citizens. The main mission of Leuven 2030 is developing a climate neutral city, in the broadest sense, by 2050. In order to achieve this ambition, an elaborated Roadmap was launched in the spring of 2019, consisting of 13 programs and further subdivided in 80 projects. Among these projects the more 'traditional' elements of reducing traffic, increasing buildings insulation, and shifting to low-emission energy can be found, together with elements like airplane traffic reduction, climate mitigation and adaptation, or a shift to local food production. Several of these latter elements connect to a footprint perspective on emissions reduction and are examples of the very high ambition level within the Roadmap.

Leuven's circular city ambition is explicitly positioned as a crucial lever: one of the programs fully embodies Leuven's CE strategy, launched at the beginning of 2020 by the Platform Leuven Circulair, with five focal elements: circular businesses, circular buildings, the concepts of repair/share/reuse, consumption, and setting up a knowledge base [39]. Key to the strategy is that it builds on an existing community ecosystem of repairing and making, local social economies, and civil society organizations such as repair cafés with the ambition to reinforce and stimulate existing and new initiatives in a strategic framework. The strategy additionally encourages circular entrepreneurship by supporting circular start-ups and industrial symbioses. Platform Leuven Circulair has been created to guard the political management, the implementation and monitoring of the Leuven 2030's circular city strategy, and the transversal management of the involved city administration departments and all concerned actors collaborating in a city wide approach. The platform brings together the city government and relevant departments, Leuven 2030, the local repair network, knowledge institutions, and company networks with strong links to the city. It organizes interactions between the involved actors and exchanges relevant initiatives in order to create synergy. It streamlines questions to the different city departments and functions as a mirror board for the respective program in the Roadmap. Hence the platform focuses on the strategy and the respective political responsibilities, while the perspective of the Roadmap program is more dynamic, with a focus on effectively implementing, building partnerships, and supporting communities. 
While there is a large overlap between a circular and a climate neutral city, climate neutrality can be considered as the 'more measurable' ambition (even if there are different ways of measuring it) compared to circularity. For climate neutrality, the desired results can be aggregated into a reduction of greenhouse gas emissions. In contrast, in many texts on the circular economy and circular cities, the goals are not clearly addressed, or implicitly assumed, connecting to a lack of consensus on the definition of a circular economy and circular cities, as discussed above. Some sources focus on economic effects in terms of jobs, economic growth, and saved money, which is evidently a too narrow focus $[40,41]$. While explicitly measurable goals have not been stated yet in Leuven's circular city strategy, it does consider the wider effects on the city in terms of inclusiveness and a local and resilient economy operating within its respective planetary boundaries. Adopting references like doughnut economics [18] and the Value Hill [42] implies that the strategy questions the core of linear extractive economic systems in favor of regenerative and redistributive economies. Also, it fits within the pursued broader effects of Leuven 2030 focusing on inclusion, livability, and resilience.

In both the Roadmap and the CE strategy, elements of both mainstream economy and of a movement to a different paradigm are clearly present, which is typical for the onset of eco-city programs [43]. Monitoring progress against the high ambition level is to be set up as such that it contributes to revealing the followed course and to providing feedback and input for adjustments. A dedicated program for monitoring has been included in the Roadmap. While the development of a complete city monitor will require time and effort, given the bottlenecks described in the previous section, it is important to consider where to find the most rewarding avenues within the city to start resolving some of the bottlenecks. Examples could be found in bottom-up transition projects. Such projects at first try to get launched while being embedded in the mainstream economy, leading to a similar tension between paradigms. With respect to monitoring the progress of such projects, a major advantage of the city context is the physical proximity between the involved actors, providing increased opportunities for bottom-up data collection.

\subsection{Practice: Realizing A Building Materials Bank Contributing to A Circular City}

In order to understand better how Leuven's CE policy ambitions can connect to real life practices and pilot projects contributing to a circular city, this paper focuses on one specific project within Leuven's circularity transition: a materials bank for building materials. Leuven's circular city strategy mentions that within the European project Pop-Machina [44], a (building) materials bank will be developed and that several existing initiatives in Leuven are already working towards what could become a "real" materials bank later [39] (p. 10). The urban materials bank is one strategic project within the circular building sub-strategy and goes hand in hand with other actions such as supporting 'building' actors in Leuven with the principles of circular building, supporting networks that can recollect and reuse building materials in the Leuven region, and setting up pilot projects for circular building. Leuven's Policy Agreement 2019-2025 furthermore explicitly incorporates keeping building materials within the urban materials cycle [45]. The city wants a system taking into account the entire lifecycle of materials; preventing waste is central as well as recycling and reuse of materials or raw materials. The city will facilitate the setup of a materials platform for building materials at an urban or city regional level, in collaboration with existing social economy initiatives, to keep these materials within the urban cycle and will install digital platforms, spare part centrals, and material banks for second hand use. Furthermore, the city aims to realize logistical systems reducing road transport in favor of water and rail bound good transfer stations and systems as well as city regional logistical platforms. In- and outflows of building and demolition materials will be facilitated regionally and reinforced via de Vaart, the end branch of the canal between Leuven and Mechelen. Last-mile-logistics delivery of building materials is key, with easy accessibility to the main road. Additionally, the city will maximize reuse of materials that become available when reconstructing the public domain. In these respects, de Vaart area is a great business location for (production) companies with circular economy business models, given its optimal accessibility, proximity of residential areas, and several 
possible synergies with existing initiatives and activities. Policy and planning frameworks (e.g., Spatial Structure Plan Leuven, Circular City Strategy Leuven, Vaartopia) direct the area towards circular area development. This offers a unique opportunity for many stakeholders to take up a concrete role and to cluster initiatives both organizationally and spatially. Furthermore, circular spatial development is anchored in documents such as Leuven's Spatial Structure Plan and Leuven's Climate Action Plan. In other words, the discussed materials bank counts as one project in a larger transition to circular building material flows.

At the time of writing (summer 2020), a building materials bank is under development in a vacant warehouse at de Vaart in Leuven. In line with the project initiators' existing activities, the materials bank starts with a focus on wood (waste) flows. The city of Leuven initiated the project, which is being executed by two existing non-profit organizations, Sociaal Atelier and Reused, who both have years of experience in Leuven with repurposing reclaimed building materials. Sociaal Atelier was founded in 2017 by three friends who felt the need for a space to work out do-it-yourself projects. It offers an open workshop where hobbyists, organizations, and semi-professionals can work with wood, metals, and electronics with or without guidance, near Leuven station. Reused was founded in 2013 with a mission to promote sustainable, affordable, and creative reuse of discarded materials. Projects are mostly furniture or interior projects for schools or other social programs. Sociaal Atelier and Reused have joined forces to realize a materials bank project in Leuven. The Flemish Waste Agency supports them with a subsidy from Circular Flanders to experiment with urban mining, stock, and reuse of (building) materials. The city of Leuven pays for a two-year lease of the warehouse through the European POP Machina project, supporting the link between makers movements and circular economy in seven European cities [44].

Building on the expertise and current activities of Sociaal Atelier and Reused, in an initial stage the materials bank focuses on the recirculation of wood (waste) originating from three sources: one to two containers per month from the intermunicipal recycling parks Ecowerf, wood recovered from de-constructing city buildings, and unsellable wooden furniture from ViTeS, the local second hand thrift store located near the city ring. Monthly meetings with the materials bank core working group (MBWG), consisting of the city of Leuven and other advisors, help to define and steer the materials bank project scope and structure. This working group develops (the process to realize) a building materials bank in Leuven collecting, processing, and selling materials. The city's goal is to have an operational materials bank by the end of 2020, steered by a non profit organization. Simultaneously, this working group feeds the city's parallel project to map Leuven's urban metabolism in order to support city wide circular resource flows. Figure 1 details the materials bank policy and actor context.

This paper addresses particular data challenges to evaluate progress and impacts of a building materials bank in combination with gathering data for overall monitoring purposes. It tries to identify which data should be collected in a circular city transition and how to do that, adopting a building materials bank as a case study. It takes multiple dimensions and scales into account, acknowledging the question as a wicked problem and proposes a combination of quantitative indicators and qualitative guiding questions in a developmental evaluation. 


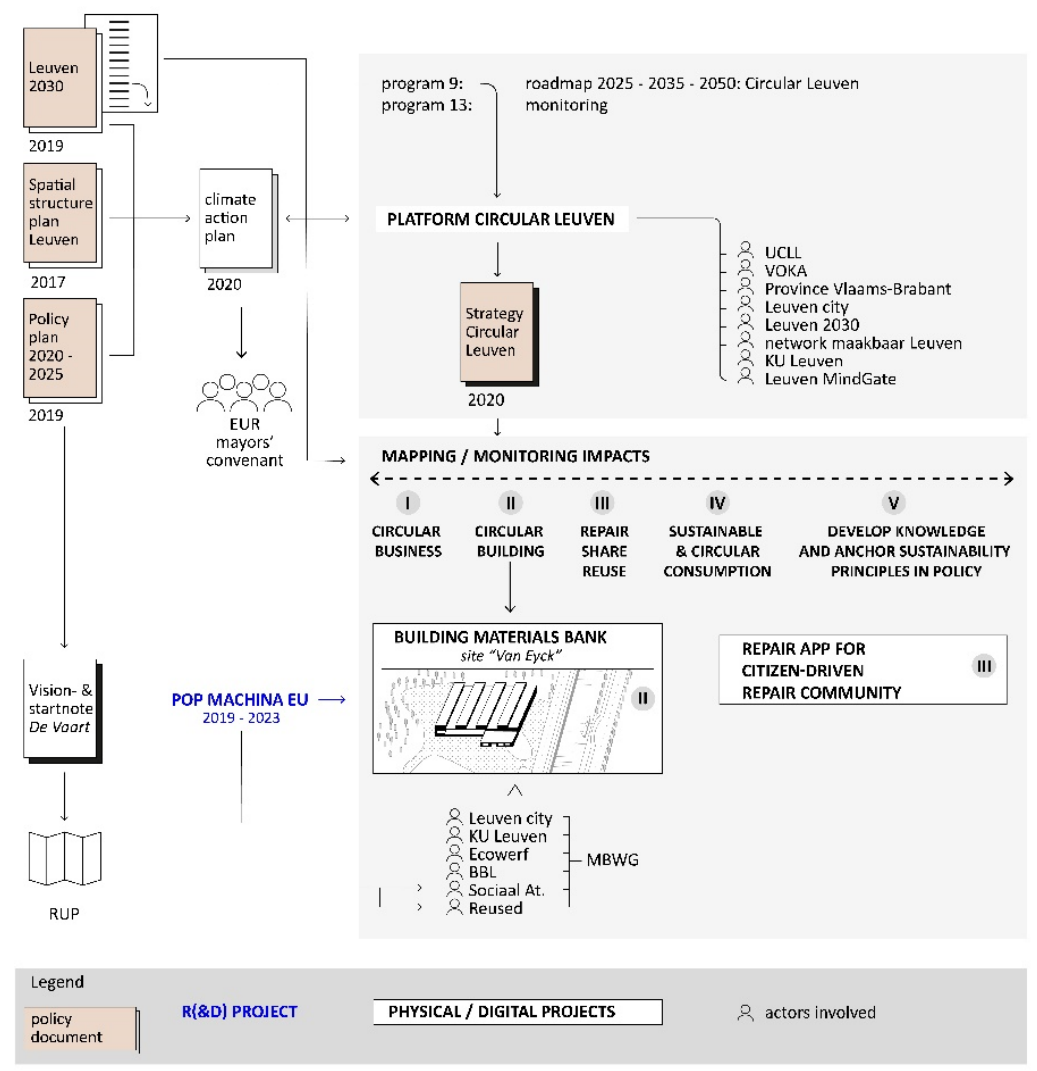

Figure 1. Policy, science, and practice context of Leuven's building materials bank.

\section{Materials and Methods}

\subsection{Participatory Action Research}

The authors are directly involved in projects within the local transition in Leuven towards a circular and a climate neutral city. While they have tangible roles within these projects, their main occupation is academic research. This allows a fruitful cycle of testing theoretical concepts in real environments and learning from and with practice, while influencing the course of real-life projects from an advising role founded in academic knowledge. In this way, the research approach can be described best as participatory action research, taking part in change processes from within, while learning from and through these changes [46]. This results in highly specific knowledge, as opposed to generalized conclusions, with a strong focus on the learning process itself.

The term action research describes research on conditions and effects of social action that simultaneously lead to social action. In the context of this paper, the scope of the research is not only social, but also belongs to the exact sciences, as the research activities focus as well on physical flows of materials and measurements thereon. Since participatory action research requires a strong sense of self-reflection on the researcher's interactions with others throughout the process [47], the following section clarifies the different author research backgrounds, their assumptions and entry points in this paper to develop a monitor for circular city projects. Additionally, the following section explains the activities the authors carried out regarding the presented results and what their roles were in practice.

\subsection{Author Backgrounds and Research Entry Points}

Julie Marin is a postdoctoral Urban Design Researcher (UDR) at KU Leuven's Department of Architecture. Her action design research addresses the circular city transition concept as a 'wicked problem', in a setting with high epistemological and ethical insecurity [31] (p. 97). Since October 2019, UDR has been a member of Leuven's Materials Bank Core Working Group (MBWG). In the 
MBWG, the UDR assists site visits and meetings while developing its own research to link the circular economy and spatial development in Leuven, which is provided to the working group (see Table 1). The UDR adopts design-based mixed methods, such as spatially mapping relevant places and actors that are part of Leuven's wood flows to reveal and synthesize invisible (spatial and actor) connections. In other words, the UDR helps to contextualize the materials bank project, adopting co-production workshops with stakeholders, complemented with semi-structured interviews, desktop policy documents, and literature reviews. Throughout this process, the UDR's action research challenges and questions existing understandings and interpretations on how Leuven's wood metabolism could become more circular and what a building materials bank's role could be in this shift.

Table 1. Activities carried out by the Urban Design Researcher (UDR) regarding the presented results in Section 3.

\begin{tabular}{|c|c|}
\hline & Activities Conducted by the UDR in Relation to the Materials Bank Core Working Group \\
\hline December 2019 & $\begin{array}{l}\text { Facilitating a one-hour stakeholders conversation on which role(s) they envision for } \\
\text { themselves within the materials bank project as well as how they would see it } \\
\text { being materialized. } \\
\text { Collecting relevant stakeholder information (relevant locations, partners, and infrastructures) } \\
\text { using a map of Leuven with the stakeholders. }\end{array}$ \\
\hline April 2020 & Assisting in a virtual site visit of reference project Buurman in Rotterdam. \\
\hline May 2020 & $\begin{array}{l}\text { Spatial mapping complemented with phone interviews to understand Leuven's wood } \\
\text { metabolism throughout the entire chain of extraction, processing, consumption, and disposal } \\
\text { to gain insights into different wood types, sizes, and possible applications and potential } \\
\text { collaborations. }\end{array}$ \\
\hline $\begin{array}{c}\text { October } \\
\text { 2019-June } 2020\end{array}$ & Assisting in MBWG meetings and bi-lateral brainstorms with the city project leader. \\
\hline
\end{tabular}

Luc Alaerts is a postdoctoral researcher at KU Leuven's Department of Materials Engineering with a focus on monitoring sustainability transitions. Within the Roadmap for Leuven 2030, he has managed the knowledge building and monitoring program from September 2019 onwards. A key deliverable in this program is the construction of a monitor for tracking progress of the Roadmap. Luc Alaerts has been involved in parallel discussions within the Roadmap regarding data and monitoring, such as the development of indicators for the progress of the strategy of Leuven Circulair, the monitoring of the impact of smaller-scale transition initiatives such as a collective renovation project and of circular businesses such as a repair shop, and on data governance for the Roadmap as a whole. While he has not been directly involved in the materials bank project itself, his direct interactions with UDR and with Leuven Circulair have been the basis of the idea development on monitoring. These ideas have been obtained from a structural collaboration with KU Leuven as a knowledge partner, which Luc Alaerts has been setting up as an additional role in the Roadmap. This role involves building up a research portfolio focusing on the challenges and bottlenecks of data gathering and governance. A hypothesis from Luc Alaerts' research is that building links between macro and micro data provides a pathway to delivering more direct policy feedback. In this way, the development of transition monitoring at the meso scale is central in his research, serving the needs of policy makers at different scales.

Karel Van Acker is a core member of the Platform Leuven Circulair, as professor at KU Leuven in the Circular Economy. He is an interdisciplinary professor at both the KU Leuven faculty of Engineering Science and the faculty of Economics and Business. His research is focused on developing strategies to realize the circular economy $(\mathrm{CE})$ and on sustainability assessments of these $\mathrm{CE}$ strategies. Based on this experience, he has mainly been active in drafting a vision and setting up a governance model for the start of Leuven Klimaatneutraal and of Leuven Circulair. He has been involved in building the content of the roadmap of Leuven Klimaatneutraal, and in advice on the priorities set by Leuven Circulair. Since the largest material flows concern the construction sector, he has put forward the idea of better organising C\&D waste recycling, and together with other experts, introduced the idea of a materials 
bank. Wood is the focus of this bank, and a PhD in Van Acker's group has been initiated on the impacts of wood cascading. Additionally, the need for better monitoring as well as better underlying data became obvious and became the crucial bottleneck for progress, leading to setting up new monitoring frameworks for the progress towards climate neutrality and towards a circular economy on assignment of Leuven Circulair and Leuven Klimaatneutraal. Both frameworks start from a consumption perspective. The challenge is to integrate consumption data with life cycle impacts sustaining this consumption.

This paper deliberately seeks to build bridges between UDR approaches broadening the scope of a circular materials bank, continuously adding relevant questions, scales, and dimensions, and the goal to monitor this messy transition process, capturing and narrowing it down to essential components.

\section{Results}

\subsection{The Materials Bank's Messy Development Process}

Figure 2 summarizes the materials bank development process between December 2019 and July 2020. Above the timeline, it lists the stages of materials bank taking shape and which actors are responsible for this process. Below the timeline, the different actions and events are listed as well as the concrete results they triggered in the materials bank development process. In the light of developing a bottom-up monitor, the timeline brings up a set of relevant geographical scales and transition dimensions that should be taken into account to keep track of how the materials bank is performing.

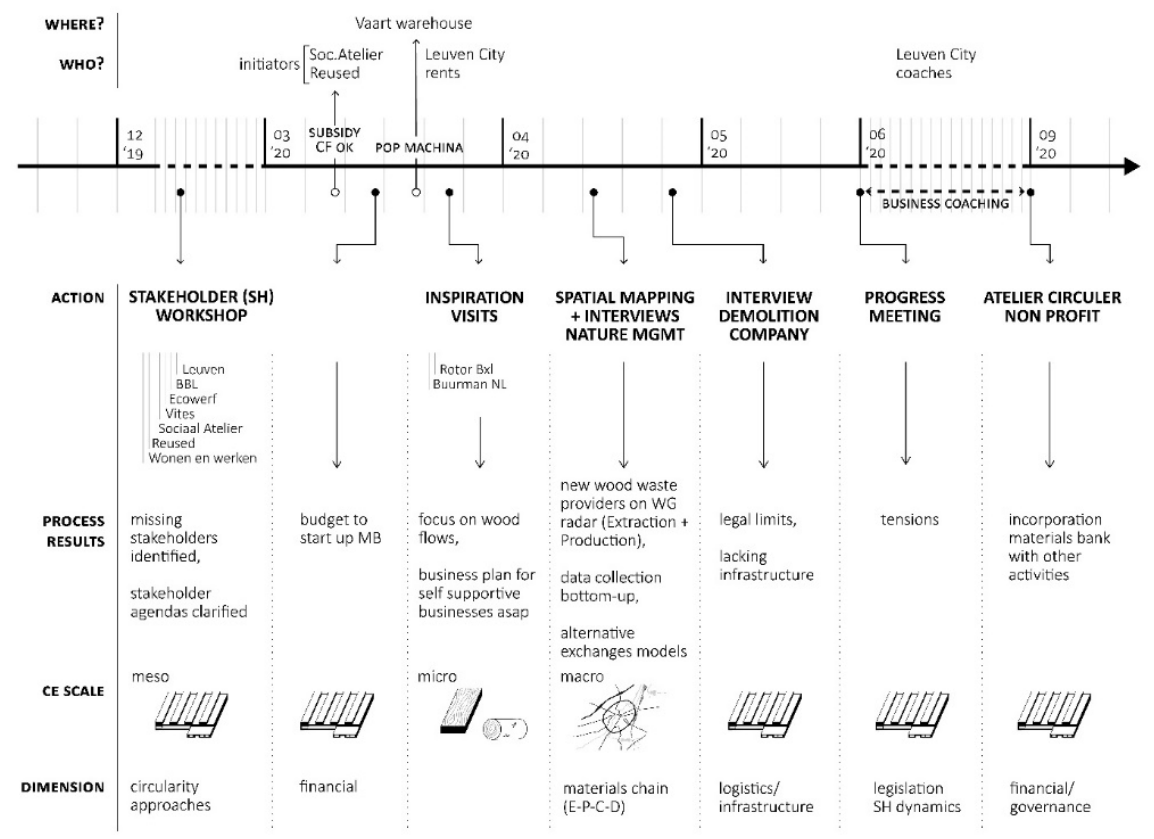

Figure 2. Timeline materials bank development process.

The next section mainly focuses on actions that are relevant for this paper objective, therefore it does not deal with all aspects (e.g., operational, marketing, and communication) of the materials bank development process. Firstly, the materials bank development process confirms that physical boundary conditions for a circular urban metabolism are highly flow and context dependent and operate at different geographical scales that should simultaneously be taken into account when developing a bottom-up monitor for a building materials bank. For the materials bank project in Leuven, the different scales can be defined as follows:

- Micro: wood waste

At the micro scale, different types of wood (waste) circulate to and from the materials bank. Initially, the inputs come from a container with reclaimed wood from the recycling park (Ecowerf), 
second hand stores (ViTeS) and urban mining in buildings. At the micro scale, it is crucial to take material characteristics specific to wood into account, such as different wood categories (clean versus contaminated), circular economy cascading principles for wood [48], and specific transportation and processing requirements. After a few months, the materials bank additionally started looking at wood (waste) inflows from landscape management. Especially here, the interdependency with landscape cycles (sustainable harvesting) becomes important to take into account.

- Meso: materials bank

The site of the materials bank along de Vaart can be considered as the meso scale. This scale includes physical and organizational facilities for storing, processing, and distributing wood (waste) flows. The degree to which the materials bank site itself contributes to circularity is strongly tied to performance of the buildings and the site themselves (e.g., materials and collaborations used for its construction, operation, and heating).

- Macro: hinterlands and wood ecosystem (logistical chains, sheds, externalities)

At the macro scale, the materials bank is tied to a hinterland of sites and areas providing and receiving wood (waste). Physical transportation infrastructures such as de Vaart, road, and rail transportation connect the entire wood ecosystem. Besides physical infrastructures, all these places are tied to each other via wood (waste) transactions [49], each having a larger spatial, social, and environmental impact that should be taken into account when monitoring.

The map in Figure 3 positions the materials bank within Leuvens' larger wood metabolism. It starts uncovering wood locations and flows in and around Leuven throughout the entire chain of extraction, processing, consumption, and disposal. Spatial mapping was complemented with phone interviews to understand different systems of nature management maintained by large public land owners in Leuven (city, university, Flemish Forest Agency). It starts by building insights in different wood types, sizes, and possible applications, puts new wood (waste) providers originating from nature management on the working group radar, and expands the MBWG focus from the 'end of the chain' to 'extraction' and 'processing' parts of the chain. In other words, the mapping and interviews build an understanding of what types of information (e.g., wood stakeholder contacts, typically available quantities, cycles of availability, wood dimensions and handling, etc.) are needed to work on circularity in all parts of the wood chain. It is a highly specific (made to measure) approach, where each different actor raises boundary conditions specific to its own mode of operation. Leuven's actual wood hinterland undoubtedly expands far beyond the administrative boundaries and also those of the map below.

The short mapping exercise revealed that how wood flows depends equally on values, goals, and definitions of the different involved parties. Furthermore, the mapping exercise showed that wood (waste) flows are highly variable, depending on unpredictable events. For example, a bark beetle plague killed 300 firs in 2019, which resulted in a lot of 'waste' wood or a buyer that no longer picked up a leftover batch of wood from a nearby forest. In conclusion, site-specific bottom-up data is required to get a precise grip on Leuven's wood (waste) flows. Mapping information such as tree species, associated wood types, and actors involved in the landscape maintenance appears equally relevant as quantitative assumptions. An Arcgis database can connect this data to exact geographical locations in order to make it useful for other actors engaging in the urban metabolism. 


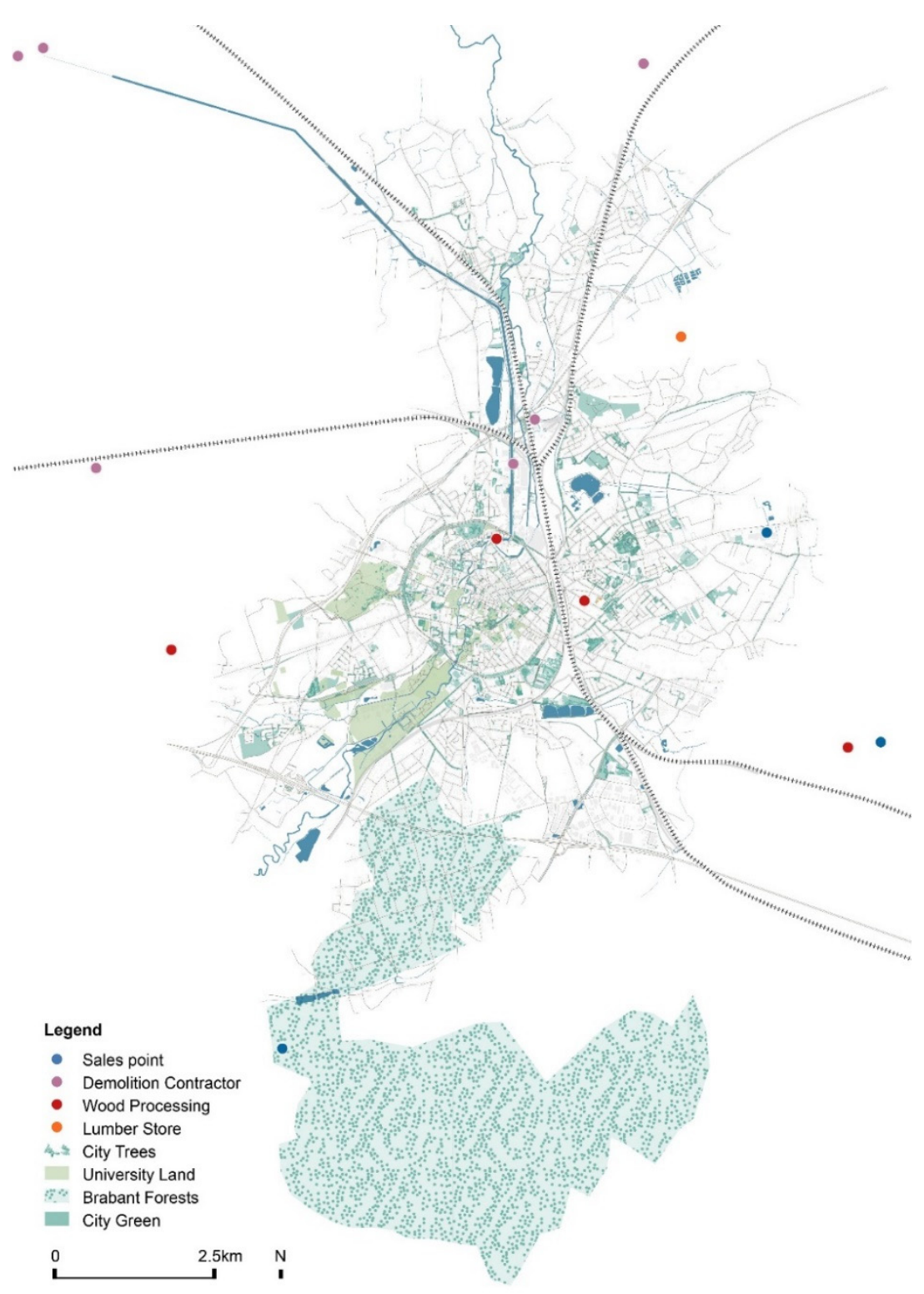

Figure 3. Wood locations and flows in and around Leuven throughout the entire chain of extraction, processing, consumption, and disposal.

Secondly, the materials bank development process identifies several relevant transition dimensions to be included in a monitor. The list below is far from complete, but nevertheless supports the argument built up in the introduction that dimensions beyond materials and energy optimization are relevant to monitor impacts and process results of bottom-up circular city projects.

- Spatial dimensions:

The entire materials chain should be taken into account (extraction, processing, consumption, and disposal). Wood (waste) flows can indeed originate from all locations where these different material related activities take place. In the case of wood flows in Leuven, this includes the forests where wood is sourced, lumber stores, wood processors, sale points, application, and disposal sites. These sites can be geographically located outside Leuven's administrative boundaries. Logistical operations' social as well as environmental impacts throughout the entire chain should be taken into account when monitoring.

- Infrastructural networks and logistics: 
Transportation of wood (waste) during the entire chain should be taken into account as well in order to be able to assess where infrastructural networks should be modified, reinforced, or created. For example, making the nearby de Vaart quay side directly accessible for water bound transportation would support the city's circularity objectives in the neighborhood.

- Stakeholder network and dynamics:

Stakeholders vary widely over the entire chain and a relevant stakeholder network can endlessly grow. A monitor should take into account that the overall circularity of wood flows in a territory depends on operations tied to each of these stakeholders. This requires a continuous follow-up with stakeholder ambitions and intentions. Missing stakeholders should continuously be added. In the case of the materials bank, a kick-off workshop in December 2019 with an extended set of mainly public stakeholders concluded that essential stakeholders such as social economy Wonen en Werken ('living and working') were missing. Additionally, actors from the private sector such as building material producers, demolition companies, logistics companies, and do-it-yourself companies that manage important building material stocks were missing in the initial conversations [50].

Another important aspect is the modus of stakeholder collaborations. The last MBWG meeting before summer 2020 made clear that clarity and transparency about intentions and expectations are key throughout the entire process. The meeting took place in the materials bank warehouse to discuss the progress and press launch planned in August. Due to the COVID-19 governmental lockdown between March and May, very little progress had been made and the warehouse was almost empty. The meeting developed in an uncomfortable atmosphere, bringing to the surface the fact that expectations between the different involved parties differed. The city decided to cancel the planned press meeting and started intensively coaching the MB initiators to develop their business plan. Indeed, industrial ecology literature increasingly points to the importance of trust and general reciprocity in industrial symbiosis projects [51].

\section{- Circularity approaches:}

Each stakeholder adopts his/her own approach to circularity. For example, the demolition and building industry mainly focuses on circularity as recycling building materials (downgrading the material), while there is also a large bottom-up community of repairing and sharing in Leuven. While all of these practices contribute to the city's overall circularity, they each operate within their own practical understanding of circular economy. The monitor should also incorporate to what extent initiatives contribute to a socially and environmentally just economy. For certain sectors, this might require disruptive innovations and modified legal frameworks to allow for higher value material reuse.

- Financial structure:

The materials bank development process made it apparent that circular city projects do not easily fit into classical business development schemes. Time pressure and limited and uncertain funding largely depending on subsidies make it difficult to set clear targets, to plan ahead, and risk directing the project into rather classical profit driven market models. After trying to realize circular wood activity in a self-sustaining way, in September 2020 this activity was grouped with three other activities (wood building and renovation projects, open workshops, and workshop events) in a new organization, named Atelier Circuler. In this construction, the three other activities can financially compensate for the currently non-profitable wood recirculation activity in the materials bank. This solution at first sight seems to solve the economic equation, nevertheless it does not guarantee fulfilling the circular city strategy mission to be environmentally and socially just. The subsidy provided by Circular Flanders in early 2020 accelerated the city's decision to support Sociaal Atelier and Reused to initiate a materials bank in a warehouse at de Vaart rented by the city for two years, as part of the Horizon2020 POP Machina project. As a return for this engagement, the city of Leuven stressed the need for Sociaal 
Atelier and Reused to develop a robust business plan that could make their materials bank financially self-sufficient as soon as possible.

In this complicated financial reality, the monitor would ideally guide the materials bank project towards a business model taking into account social and environmental externalities both locally and globally. It should incorporate how money flows within the project and to what extent it contributes to 'regenerating nature' and 'redistributing resources' fairly, as illustrated with the key principles of a doughnut economy [18].

Exchanges between the MBWG and the Flemish Forest Agency for example brought to the surface an interesting alternative financing system coming down to 'wood for work'. Such an exchange system could be an opportunity for the materials bank to contribute to the economic paradigm change independent from conventional financing systems that do not take into account negative externalities, as they also exist in wood trading.

- $\quad$ Legal aspects (Policy)

As part of the urban development plan to accommodate circular economy activities in the de Vaart area, the materials bank development process brought to the surface legal conditions that limit circular activities. For example, an interviewed demolition company processing wood waste from demolished buildings to turn it into semi-finished products such as fibers to burn (cat. B wood) or chipboards (cat. A wood) raised the question of why the materials bank would legally be allowed to upcycle materials when this company is only allowed to process these materials into semi-finished products. In conclusion, Flemish regulations labeling reclaimed materials as waste or not waste is a current bottleneck that is preventing a circular economy from accelerating.

In summary, the materials bank project is gradually taking shape 'on the go', flexibly adapting to possibilities and opportunities as they present themselves. For example, Sociaal Atelier and Reused were taken on board to execute the project after they were granted a subsidy by the OVAM. The warehouse was selected from a few possible locations and is now leased with budget from European POP Machina project. Wood (waste) inflows are gradually tested and selected through new contacts, site visits, and tests with for example landscape managers. Inspirations come from various inputs, such as exchanges with other building materials banks such as ROTOR Brussels and Buurman, Rotterdam. After a virtual Rotterdam visit, the Leuven materials bank for example started developing a 'city wood line', producing kitchen planks from reclaimed wood from a deconstructed nearby historical building. Gradually, different pieces of the puzzle start falling into place for the materials bank as one project within a larger strategic vision for a circular city.

The above reflects the inherent 'messiness' of a circular city transition project. It touches upon multiple dimensions (legal, technical, financial, and human interactions and normative frameworks) that are all interrelated in the transition. The key challenge is to capture this complexity when evaluating the material bank impacts.

\subsection{How to Monitor the Performance of A Materials Banks, and How to Link This Performance to A City-Wide CE Monitoring?}

While several material banks, or, by extension, industrial symbiosis systems, are operational and projects supporting such initiatives with tools are in place [52], no comprehensive monitor directly applicable for this kind of project has been developed yet. At a more general level, knowledge development in the assessment of circularity of projects is premature. Only one example was found, developed within the H2020 SCREEN-Lab project [53]. In this tool, the scores on nine criteria are aggregated into one number expressed in euros. In the criteria, there is a strong focus on waste and recycling. Criterion selection seems to have been driven by data availability. Due to the aggregation into one number and the very limited attention for indirect effects of projects, a rather narrow focus to $C E$ is being provided. On the other hand, the tool highlights a few key elements of circularity assessments: avoided virgin input, avoided waste, and reduced climate impact. 
To make a start with a monitor for a materials bank, in first instance, transactions can be listed and details can be gathered (see Figure 4). Every shipment of left-over wood that finds a secondary application can be expressed as avoided waste and also as avoided emissions in terms of the carbon sequestration property of wood. Moreover, the avoided virgin materials in the process to convert the wood into a secondary application can be added as well in the assessment. Next, emissions due to the involved logistics and the process to obtain a secondary application need to be added as well. Other impact categories beyond greenhouse gas emissions could be included using Life Cycle Assessment (LCA) [54].

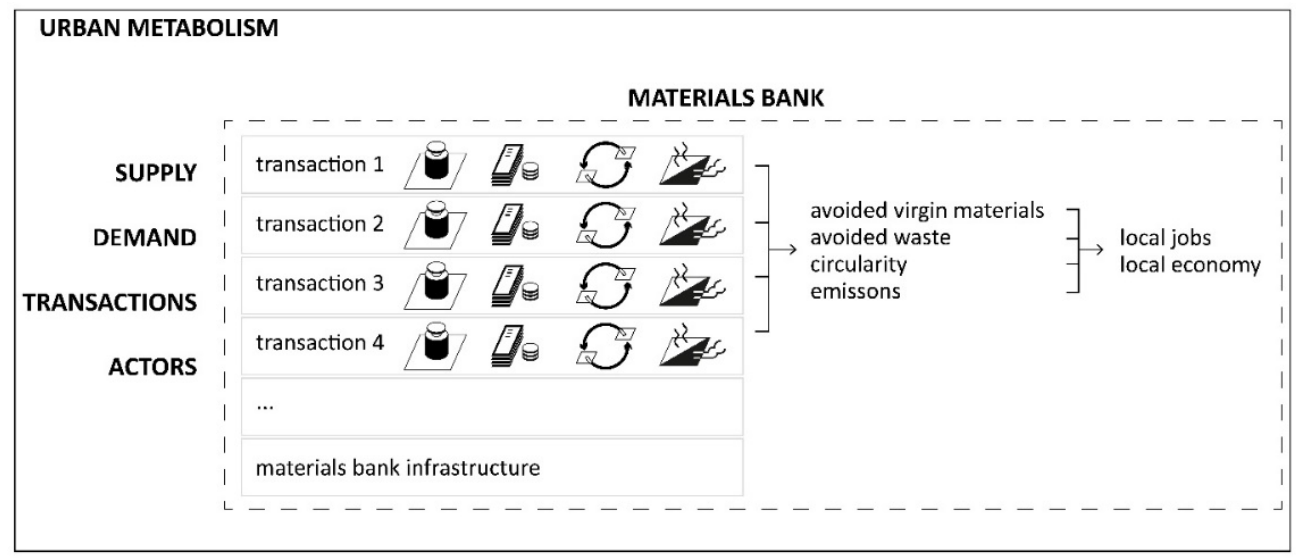

Figure 4. Schematic overview of a possible approach to make a start with monitoring the materials bank performance.

A next challenge is to assess circularity by comparing the quality of the secondary application with the original one. In a CE, materials are meant to be used at their highest application potential for as long as possible [17]. If the secondary application would be the same or very similar in quality to the primary one, this is to be preferred. As an example, wood beams converted to particle boards are to be valued lower than wood beams converted to smaller beams in a subsequent application. Tools to quantitatively assess such forms of cascading are still in development [48]. For the moment, a number of other parameters could be measured, like the size or contamination degree of wood beams.

For the materials bank as a whole, the above numbers on avoided virgin inputs, avoided waste, and avoided emissions need to be summed and lumped with operational data from the materials bank infrastructure, like the emissions of its warehouse. These overall data could next be integrated into the city-level material flow analysis and emissions. Also aggregated circularity scores would be desirable, in so far as they could be available for individual transactions and in so far it would be possible for instance to add up data on cascading. A materials bank could also provide local jobs and activities and contribute to a resilient city economy. Proxy indicators for these aspects could be the revenue and the amount of direct jobs generated [54], which can on their turn be integrated into the overall city economic numbers.

Taking a wider perspective of the materials bank as one pilot project within a city-wide effort to become circular, the materials bank would benefit from spatial mapping of wood metabolism in the hinterland of the materials bank, as was explored by the UDR (see Figure 3), allowing us to reveal potential actors, along with available or expected materials and demands. This could prepare the way for growing the materials bank from an initiative taking care of leftovers into a platform managing and optimizing wood flows in the hinterland. As discussed in the previous section, this hinterland is not identical to the administrative boundaries of the city, but there will be a large overlap.

It is very clear from the above that data gathering will be a major bottleneck in such bottom-up data gathering. The Amsterdam example mentioned in the introduction is illustrative of the time and effort that go into the creation of new datasets [36]. The Flanders example has been elaborated up to 
the level restricted by openly available data [55]. In the latter study, data from open sources, in most cases from the respective government instances or organizations with related duties, have been used. The research has revealed that an improved version of a monitor could be made if access could be provided to more detailed data on products and materials and their use, which are often protected for reasons of privacy, intellectual property, or commercial value. Hence stakeholder interaction and collaboration will be crucial in order to make progress, as these variables will determine the availability and quality of the data. Indeed, additional efforts would be required from actors engaging in a materials bank transaction, as they need to deliver details e.g., on quality of the wood, on the applied process, and/or on the secondary product. In the start-up phase, the assumed positive attitude around the project might perhaps translate into openings for creating and sharing the data. In the course of time, stakeholder management would have to grow as such that stakeholders transfer data from an idea of individual gain, like the ability to increase the value of transactions, while contributing to a broader gain, i.e., developing products and using materials with a better sustainability profile in a resilient local economy system.

Besides quantitative data and indicators, Section 3.1 makes clear the need for an evaluation and/or guidance framework that incorporates all relevant dimensions and scales. One recently developed framework may be very helpful in this context. The City Doughnut model mentioned before frames urban transition via four lenses that, applied to Leuven's materials bank project, could serve as guiding questions to be taken along in the development process [24]:

- What would the materials bank mean for the people of the city to thrive? The materials bank can provide local production and local employment (including the social economy), with the potential to contribute to an inclusive and resilient city where different actors are in fact helping each other by exchanging material flows.

- What would the materials bank mean for the city to thrive within its natural habitat? The materials bank can become a component in realizing local and sustainable wood flows, while contributing to the reinforcement of natural infrastructures and habitats.

- What would the materials bank mean for the city to respect the wellbeing of people worldwide? In a global context, the activities of the materials bank could contribute to fairer consumption by excluding exploitation of people in any part of the wood supply chain. While this may seem a long shot, compare for instance alternative labor and societal conditions in wood harvesting in distant countries.

- What would it mean for the city to respect the health of the whole planet? The materials bank could be seen to contribute to decreasing deforestation in distant regions by using locally obtained inputs, as such helping to balance natural cycles worldwide, thereby enabling nature to regenerate from any wood flow impact.

These questions could be answered to a limited extent via the integration of data on material flows, saved emissions, and jobs into the city-wide numbers. However, monitoring elements like quality of jobs or resilience of the economy and demonstrating evidence in causal relations with broader effects worldwide is much more challenging and can for the moment only be touched upon in qualitative ways.

\section{Discussion}

This paper navigates within the so-called policy-practice-science interface, a topic which urban metabolism researchers continue to explore [56] to push the boundaries of their own disciplines while contributing to real world impacts. Weichselgartner et al. [57] identify barriers to knowledge transfers between science, policy, and practice such as "divergent objectives, needs, scope, and priorities; different institutional settings and standards, as well as differing cultural values, understanding, and mistrust". The authors advocate for "knowledge systems ... that overcome technocratic reductionisms, integrate an extended range of sources and types of information, and engage in the collaborative production of 
knowledge through the interaction of producers and users, thus enhancing the quality of associated decision making." [57] They furthermore acknowledge that properly embedding knowledge transfer in research processes and policy making requires time, space, and financial resources [57,58]. Perrotti adds the importance of clearer engagement with the political space and power relations into which planning processes are embedded [58]. The goal of this paper has been to produce knowledge useful for policy, practice, as well as science.

\subsection{Bottom-Up Data Gathering}

The above sections have described that current top-down data collection, and monitoring at the urban level is limited to openly available and accessible datasets that have been gathered in contexts different from CE. Bottom-up data collection can be a complementary pathway, nevertheless requiring enhanced stakeholder interaction. However, given concerns on intellectual property, commercial positions, and/or privacy, data owners' reluctance to share will only be overcome if they understand the added value from their own perspective. In this respect, a project like the materials bank may show an avenue to engage stakeholders, as the success of a materials bank (or any other circular city initiative) can only be built upon the positive support of a group of stakeholders. The materials bank project can also be seen as a learning experience; capturing the learnings can best take place when data are available to evaluate its performance, which is in fact required to maintain support from investors, local politicians, and participating stakeholders. The start-up phase of the materials bank provides a crucial moment to consider which data would be ultimately needed to demonstrate impacts to make sure that immediate and maximal advantage is obtained from stakeholder collaboration in the project.

While some of these data may be readily available, sometimes more complex assessments of logistics, production processes, and assumptions on the future use of products may be desired. Data on quality of wood, data allowing comparative assessments of different ways in which circularity of transactions could be materialized and more refined economic performance data including externalities would be especially needed. Moreover, aggregating such multidimensional properties into numbers is not possible in a standardized way, and sometimes trade-offs can be encountered: e.g., how to compare a long-lasting product with one that is easily dismountable [16,48]. A major question for this paper is what are the (new) types of datasets feeding the materials bank evaluation. A thorough investment in further identifying and selecting wood waste flows through stakeholder interviews and spatial mapping could be a way forward, as was briefly discussed in Section 3.1. Such efforts in mapping urban metabolism might also open up towards a future broadening of the materials bank from a platform trying to make the best of leftovers towards an optimal local management of wood metabolism in the city. In this context, it is important to realize that the hinterland of the materials bank does not coincide with the administrative boundaries of the city, though given its physical location in a city, the overlap with the hinterland of the city will be very large.

The meso level of a materials bank can help to bridge top-down versus bottom-up approaches in data gathering. While top-down data gathering risks getting stuck in making a (too) rigid framework to present data that is not able to capture the dynamics of a transition, bottom-up data gathering may result in diverse data sets that are difficult to link into a transition story. A focus on those data that are able to demonstrate real impacts in terms of direct results and broader effects of running projects may lead to tangible progress in transition monitoring. With this focus in mind, bottom-up data collection can be tailored towards the needs of the project, while a later integration of such performance data in a city monitor will help its further tailoring towards monitoring the impact on city transition.

In this case study, the materials bank project has been rather framed as a methodologically ideal concept, in contrast to the current state of the project, which is in a germination stage. While based on the perspective of this paper the materials bank is not to be seen as instrumental with respect to the ideal concept, the difference between the ideal picture and the current state has repercussions on the expectations with respect to data gathering. Specific advices on data gathering have been given above, but the pressure of making the project run in the current start-up phase may simply 
not allow much room for dedicated data gathering-on the contrary, this would most probably be considered as a supplementary, undoable effort. In order to move beyond this bottleneck, it may be helpful to realize that attaching data to materials in fact prepares the way for value creation. The more specific data on the materials created and gathered, the more value generated from transactions in the materials bank (also beyond monetary value). At the same time, these data will most probably be also the ones making the real impact of the materials bank visible. The efforts to gather data need to be clearly considered in the materials bank management as an investment which will pay off in terms of improved performance of the project. As a first step, the materials bank is already digitally labeling incoming and outcoming materials.

\subsection{Monitoring Broader and Indirect Effects}

The elements discussed in Section 3.2 for monitoring a circular city project are still quite materials and energy focused. The only more societal dimensions are the revenue and the creation of new jobs. Following Wallin's classification of living lab approaches [59], from a 'technocratic' point of view, wanting to assess and evaluate the materials bank's circularity performance narrows the focus down to avoiding waste and emissions by closing building material loops. On the other hand, when considering the materials bank from a sociocratic point of view within a larger societal transition, e.g., towards an environmentally and socially just city, the materials bank development mediates in complex actor settings by investigating combinations of interrelated problems beyond optimizing wood flows.

In order to expand monitoring beyond the level of technical performances of material flows towards broader economic, social, and environmental effects, the data gaps are very prominent and pose a risk in themselves, as data availability may shape the lenses through which the materials bank will be evaluated. Indeed, developing indicators is not a neutral endeavor, as they may eventually become connected to project targets, especially in those areas where setting the target is still in development. As an example, while it would be ultimately desirable to demonstrate the extent to which the materials bank is contributing to a local and resilient economy, an immediately available proxy parameter would be the revenue of the materials bank. Focusing on the revenue, while an increase could be considered at first instance as an evolution worth striving for, it is doubtful whether an increasing revenue would automatically align with a local and resilient economy. If such a parameter would become a leading one later on to judge the materials bank performance, it may rather push the materials bank towards a mainstream, profit-driven economic management, thereby losing any opportunities to reinforce the local economy and society. It also connects to the discussion above on subsidies; while being able to work without subsidies may seem like an ideal short-term target for the project, it may also accelerate the project towards the mainstream economy. As introduced in Section 3.2, the so-called City Doughnut has the potential to be helpful in this context. The integration of data of the materials bank into a wider city monitor will allow us to demonstrate its contribution to the broader effect of the city in part.

\subsection{Developmental Evaluation of the Transition Process}

Section 3.1 has reconstructed the so called 'messy' process of the materials bank that is inherent to societal transitions. From that perspective, the uncomfortable MBWG meeting in June 2020 might have been the result of an imbalance between involved parties' expectations and agreements on where to go and what to prioritize. Pushed by financial and operational targets that understandably do not leave much time, space, and resources for 'learning and experimenting', avenues that could truly lead to a regenerative and redistributive economy, such as alternative exchange systems outside the monetary system (e.g., wood for work) get little attention while the focus on developing a robust business plan is prioritized. From the perspective of this paper, the key challenge for the MBWG is to be mindful of the unavoidable tensions between a business-as-usual financial model vs. a utopic project with an unknown pathway while the surrounding financial flows are still following conventional criteria.

In regards to monitoring, acknowledging the materials bank as a sociocratic living lab, other developmental evaluation tools than quantitative indicators are required. From this perspective, 
connecting involved stakeholders in a learning network offering space to learn and explore is crucial. It should provide a built-in learning strategy to learn while experimenting and to make sure the right people talk to each other and information is successfully distributed and exchanged. Previously, it has been argued that the beginning of a project is a crucial time to set up data gathering and to consider what to start to measure. This imposes a lot of pressure to immediately do the right things in a right way, which is impossible given the 'messy' context of a transition. Instead, the focus on monitoring needs to be as well on learning, as it will gradually take shape along the way. Hence both the materials bank and the monitor are going back and forth between testing and reflecting, digging into the concrete and wondering what to monitor and how to do it through mixed methods and continuously connecting scales and levels.

\subsection{Clarifying and Resolving Legal Bottlenecks}

Coming to the license to operate the materials bank, the description above might suggest that it is operating in a kind of shadow zone, trying to make the best use of leftovers which are not always well documented. However, materials bank transactions need to take place in full conformity with waste regulations. For a smooth performance of the materials bank, additional efforts will be needed as every transaction has to be checked against regulation, and in some of the transactions obtaining effective permission for further use will require additional actions. Uncertainties on the possibilities of particular inputs will be present as long as a permission has not been granted. The evolution of the materials bank would be helped a great deal if a more general framework for judging transactions would become available, or via the creation of a temporary zone in the materials bank hinterland in which regulation is being applied less strictly. Solving this bottleneck would also enhance stakeholder interactions. However, this cannot be solved from the city level, as waste regulations are usually installed from the regional or state level. The stakeholders of the materials bank, among which a number of experience experts on regulation can surely be found, could be in first instance consulted for defining an approach how to solve this bottleneck.

\subsection{Lessons Drawn for the Management of the Materials Bank}

A few concrete lessons can be drawn for further development of the materials bank, as well as other circular city projects in relation to circular city monitoring:

- Organize bottom-up data collection for circular city monitoring from the very start

- Set up an organizational system to facilitate contact and data exchange between stakeholders. e.g., an open source map geographically locating stakeholders in the material flow ecosystem, including relevant information on their potential roles in circular flows.

- Acknowledge and take into account the difficult path to defining new roles and engagements with all stakeholders and to achieve collaboration in an atmosphere of trust and transparency with clear expectations and hesitations.

- Define the role of the local government as flexibly as possible: from a facilitator and supporter to an intensive business coach and data harvester, simultaneously capturing bottlenecks in other forms of legislation.

- $\quad$ Pay attention to the different circular economy approaches and to what extent they contribute to an environmentally and socially just city.

\section{Conclusions}

In this case study, tensions taking place in transition, transition monitoring, and the interplay between the two have been described. These can be summarized as an interplay between a more divergent approach, from a concern to really transition towards certain goals, and a more convergent approach, from the need to report progress and provide feedback. These tensions trickle down to a 
number of tangible findings when it comes to gathering data and building up a monitor integrating components that are essentially not measurable.

Firstly, the case study shows that designing a monitor for circular city projects simultaneously requires designing the process in which such a monitor takes shape, is tested and evolves. Given the high complexity and uncertainties inherent to circular city transition, this means that a circular project monitor should closely interact with the process it is monitoring. More concretely, such a monitor should function as a sounding board throughout all project phases, feeding and receiving feedback from the project development process. As such, it should strategically respond to what is unfolding, as an evolving tool supporting developmental evaluation in circular city transition supporting ongoing learning and direction changes, developing new monitoring mechanisms as goals evolve and emerge, as well as producing context-specific understandings capturing interdependencies [30].

Furthermore, in order to take into account societal and environmental dimensions at local and global scales, quantitative energy, materials, and job creation indicators should be complemented with a qualitative framework. The combination of quantitative indicators and qualitative guidelines creates 'space' for developmental evaluations that are crucial to transition incorporating geographical scales and transition dimensions. The City Doughnut guiding questions can serve as an example of such qualitative guidelines. Acknowledging the tensions between a 'messy' transition process and a monitoring to be based on measurable data, pressure can be removed from the ambition to reach quantitative targets, as 'developmental' evaluation of the transition process goes hand in hand with the challenges in data governance. While a focus on harder targets and indicators is an essential part of project management, in the context of the more messy transition work, it needs to be balanced with critically questioning the current project course against initial ambitious (and perhaps practically unmeasurable) goals; meeting these goals will in the end determine whether the project was truly successful. If the required data are not immediately available, a premature choice for proxy indicators could be considered, but the associated risk of locking-in the materials bank prematurely into the existing economic paradigm needs to be critically assessed over time.

As a next step, further attention will have to be devoted to the particular challenges with respect to data governance, which appeared as a major bottleneck in this case study. On the way towards an enhanced data governance, protection of intellectual property, of commercial value or of information revealing the business position of companies, or a more general reluctance to share data when the associated benefits are not clear may all hamper data sharing for monitoring purposes. To solve such complex issues, additional research on the legal aspects of data use is recommended. Investing in and setting up further research on intense stakeholder engagement is recommended as an avenue to make real progress in data availability and accessibility. When such processes are set up, together with making the connection between data gathering and bottom-up projects that are already happening (such as the materials bank in Leuven), the potential to accelerate the process to compile a monitor may be revealed. The dynamism of motivated stakeholders and their trust-based partnerships could be connected from the very beginning to data gathering showing core results and broader effects of such projects, and, by extension, showing part of the city-wide transition monitoring. At the same time, the gathered data will help to accelerate the impacts of projects themselves.

All of the above could be equally well applied to other circular projects taking place in cities, like repair cafés or circular (e.g., packaging-free) shops. Facing similar challenges but also having their particular contexts, this would create additional learning opportunities. In this respect, it has to be mentioned that circular initiatives are all too often taken for granted as being beneficial or are seen as bearing the potential to bring major change, but only with good data and systems thinking can such claims be thoroughly and truthfully investigated [55]. In the end, it needs to be understood that, instead of being a mere cost, investments in bottom-up data gathering through stakeholder networks effectively prepare the way for increasing material value and will eventually pay off in increased project performance. 
Author Contributions: Conceptualization, J.M.; Investigation, J.M. and L.A.; Methodology, J.M.; Supervision, K.V.A.; Visualization, J.M.; Writing—original draft, J.M. and L.A.; Writing-review \& editing, J.M. and L.A. J.M. wrote the first draft of the manuscript and developed all parts of the materials bank development process, as well as her own role within that process. J.M. developed Figures 1-3 and the Graphical abstract. L.A. compiled the sections on the state-of-the-art of current monitoring at the city level, while his role from a research perspective was discussing how to set up a monitor of the materials bank. J.M. and L.A. both contributed the to discussion and conclusion, the description of Leuven 2030 and Platform Leuven Circulair, and the more general parts of the introduction describing the circular economy and circular cities. K.V.A. is proceeding with action research as a member of the Circular City council, contributed to the discussion section based on field experience, and also contributed to the general storyline of the paper. All authors have read and agreed to the published version of the manuscript.

Funding: This research was funded by Research Foundation-Flanders (Julie Marin grant number 12Z9420N), the Circular Economy Policy Research Centre, and Leuven 2030.

Acknowledgments: J.M. thanks the Research Foundation-Flanders (F.W.O.) for funding her postdoctoral research. L.A. is very grateful for financial support received from the Flemish administration via the Steunpunt Circulaire Economie (Circular Economy Policy Research Centre). This publication reflects the authors' opinions, not those of the Flemish administration. The Flemish administration will not carry any liability with respect to any use that can be made of the produced data or conclusions. The authors are also grateful to numerous stakeholders for extended discussions and comments. L.A. is grateful for funding by Leuven 2030 for coordination of the Roadmap program on knowledge building and monitoring. All authors would like to thank Sarah Martens for sharing her insights on action research as developed in her doctoral dissertation "What is public? An approach to stage a debate in a village as a spatial practitioner" (UHasselt, 2018), Jessie Van Couwenberghe, Jan Mertens and Daan Van Tassel, involved in Leuven 2030 (S.M. and J.V.C.), as well as Platform Leuven Circulair (J.V.C. and J.M.) and the Leuven city administration (J.V.C. and D.V.T.) for their feedback on the paper and Britt Van Rompaey for her support with Figures 1,2 and 4, and the graphical abstract.

Conflicts of Interest: The authors declare no conflict of interest. L.A. wishes to state that the funding from Leuven 2030 received for his role in the Roadmap has the objective translation of practical needs into academic research questions as one of the finalities.

\section{References}

1. City of Amsterdam. Amsterdam Circular Strategy 2020-2025; City of Amsterdam: Amsterdam, The Netherlands, 2020; Available online: https://www.amsterdam.nl/en/policy/sustainability/circular-economy/ (accessed on 9 December 2020).

2. Paris City Council. Paris Circular Economy Plan. 2017. Available online: https://www.paris.fr/pages/ economie-circulaire-2756 (accessed on 9 December 2020).

3. Government of the Brussels-Capital Region. Brussels Regional Program for a Circular Economy 2016-2020 (BRPCE). 2016. Available online: https://www.circulareconomy.brussels/a-propos/le-prec/?lang=en\#: $\sim\{\}:$ text=On\%2010\%20March\%202016\%2C\%20the,million\%20for\%20the\%20year\%202016.\&text=To\%

20transform\%20environmental\%20objectives\%20into\%20economic\%20opportunities (accessed on 5 December 2020).

4. London Waste and Recycling Board. London's Circular Economy Route Map. 2017. Available online: https://www.lwarb.gov.uk/wp-content/uploads/2015/04/LWARB-London\%E2\%80\%99s-CE-routemap_16.6.17a_singlepages_sml.pdf (accessed on 9 December 2020).

5. Glasgow Chamber of Commerce, Zero Waste Scotland, Glasgow City Council and Circle Economy Circular Glasgow: A Vision and Action Plan for the City of Glasgow. 2016. Available online: https://circularglasgow. com/wp-content/uploads/2019/01/Glasgow-City-Scan.pdf (accessed on 9 December 2020).

6. UNEP. Brussels Capital Region: Circular Economy Transition. 2018, p. 32. Available online: https: //www.circulareconomy.brussels/wp-content/uploads/2019/04/GIREC_Brussels-report_Final.pdf (accessed on 9 December 2020).

7. World Bank. Urban Development Overview. 2017. Available online: https://www.worldbank.org/en/topic/ urbandevelopment/overview (accessed on 5 December 2020).

8. Kirchherr, J.; Reike, D.; Hekkert, M. Conceptualizing the circular economy: An analysis of 114 definitions. Resour. Conserv. Recycl. 2017, 127, 221-232. [CrossRef]

9. Korhonen, J.; Nuur, C.; Feldmann, A.; Birkie, S.E. Circular economy as an essentially contested concept. J. Clean. Prod. 2018, 175, 544-552. [CrossRef] 
10. Korhonen, J.; Honkasalo, A.; Seppälä, J. Circular Economy: The Concept and its Limitations. Ecol. Econ. 2018, 143, 37-46. [CrossRef]

11. Ghisellini, P.; Cialani, C.; Ulgiati, S. A review on circular economy: The expected transition to a balanced interplay of environmental and economic systems. J. Clean. Prod. 2016, 114, 11-32. [CrossRef]

12. Merli, R.; Preziosi, M.; Acampora, A. How do scholars approach the circular economy? A systematic literature review. J. Clean. Prod. 2018, 178, 703-722. [CrossRef]

13. Bocken, N.M.P.; Olivetti, E.A.; Cullen, J.M.; Potting, J.; Lifset, R. Taking the Circularity to the Next Level: A Special Issue on the Circular Economy. J. Ind. Ecol. 2017, 21, 476-482. [CrossRef]

14. Paiho, S.; Mäki, E.; Wessberg, N.; Paavola, M.; Tuominen, P.; Antikainen, M.; Heikkilä, J.; Rozado, C.A.; Jung, N. Towards circular cities-Conceptualizing core aspects. Sustain. Cities Soc. 2020, 59, 102143. [CrossRef]

15. Prieto-Sandoval, V.; Jaca, C.; Ormazabal, M. Towards a consensus on the circular economy. J. Clean. Prod. 2018, 179, 605-615. [CrossRef]

16. Moraga, G.; Huysveld, S.; Mathieux, F.; Blengini, G.A.; Alaerts, L.; Van Acker, K.; De Meester, S.; Dewulf, J. Circular economy indicators: What do they measure? Resour. Conserv. Recycl. 2019, 146, 452-461. [CrossRef]

17. Alaerts, L.; Van Acker, K.; Rousseau, S.; De Jaeger, S.; Moraga, G.; Dewulf, J.; De Meester, S.; Van Passel, S.; Compernolle, T.; Bachus, K.; et al. Towards a more direct policy feedback in circular economy monitoring via a societal needs perspective. Resour. Conserv. Recycl. 2019, 149, 363-371. [CrossRef]

18. Raworth, K. Doughnut Economics: Seven Ways to Think Like a 21st-Century Economist; Random House Business Books: London, UK, 2017.

19. Arnsperger, C.; Bourg, D. Vers une économie authentiquement circulaire. Revue de l'OFCE 2016, $145,91$. [CrossRef]

20. Girardet, H. The Gaia Atlas of Cities: New Directions for Sustainable Living; Gaia Books Limited: London, UK, 1996.

21. Ellen Macarthur Foundation. Towards the Circular Economy. 2013; Volume 1. Available online: https://www.ellenmacarthurfoundation.org/publications/towards-the-circular-economy-vol-1-aneconomic-and-business-rationale-for-an-accelerated-transition (accessed on 9 December 2020).

22. Marin, J.; De Meulder, B. Interpreting circularity. Circular City Representations Revealing Transition Drivers. Sustainability 2018, 10, 1310. [CrossRef]

23. Boeri, A.; Gaspari, J.; Gianfrate, V.; Longo, D.; Boulanger, S.O. Circular city: A methodological approach for sustainable districts and communities. WIT Trans. Built Environ. 2019, 183, 73.

24. Fanning, A.L.; Krestyaninova, O.; Raworth, K.; Dwyer, J.; Hagerman Miller, N.; Eriksson, F. Creating City Portraits. A Methodological Guide from the Thriving Cities Initiative. 2020, p. 44. Available online: https://doughnuteconomics.org/Creating-City-Portraits-Methodology.pdf (accessed on 9 December 2020).

25. Gravagnuolo, A.; Angrisano, M.; Girard, L.F. Circular Economy Strategies in Eight Historic Port Cities: Criteria and Indicators Towards a Circular City Assessment Framework. Sustainability 2019, 11, 3512. [CrossRef]

26. Reichel, A.; De Schoenmakere, M.; Gillabel, J.; Martin, J.; Hoogeveen, Y. Circular Economy in Europe. Developing the knowledge base. Agency Rep. 2016, 2, 2016.

27. Potting, J.; Hekkert, M.P.; Worrell, E.; Hanemaaijer, A. Circular Economy: Measuring Innovation in the Product Chain; PBL Publishers: The Hague, The Netherlands, 2017.

28. Potting, J.E.; Hanemaaijer, H.; Delahaye, R.; Hoekstra, R.; Ganzevles, J.; Lijzen, J. Circular Economy: What We Want to Know and Can Measure; Publication Number 3217; PBL Netherlands Environmental Assessment Agency: The Hague, The Netherlands, 2018; Available online: https:/www.pbl.nl/sites/default/ files/downloads/pbl-2018-circular-economy-what-we-want-to-know-and-can-measure-3217.pdf (accessed on 9 December 2020).

29. Rittel, H.; Webber, M. Dilemmas in a General Theory of Planning. Policy Sci. 1973, 4, 155-169. [CrossRef]

30. Gamble, J. A Developmental Evaluation Primer. 2008, p. 69. Available online: https://mcconnellfoundation. ca/wp-content/uploads/2017/07/A-Developmental-Evaluation-Primer-EN.pdf (accessed on 9 December 2020).

31. Vandenbroeck, P. Het Herpositioneren en Verder Versterken van de Visie (Vorming) van Plan C-Vlaams Transitienetwerk Duurzaam Materialenbeheer. 2013, p. 114. Available online: https://issuu.com/vlaanderenbe/docs/5793ae2a-35dd-4615-905a-8fc2e195a5f4 (accessed on 9 December 2020). 
32. Ecorys. Indicators for Circular Economy (CE) Transition in Cities-Issues and Mapping Paper (Version 4). 2019. Available online: https://ec.europa.eu/futurium/en/system/files/ged/urban_agenda_partnership_on_ circular_economy_-_indicators_for_ce_transition_-_issupaper_0.pdf (accessed on 9 December 2020).

33. Wilts, H.; Steger, S. CIRCTER-Circular Economy and Territorial Consequences Applied Research Final Report Annex 10 Measuring Rban Circularity Based on a Territorial Perspective Version 10/10/2019. 2019. Available online: https://www.espon.eu/sites/default/files/attachments/CIRCTER\%20FR\%20Annex\%2010\% 20Measuring\%20urban\%20circularity_0.pdf (accessed on 9 December 2020).

34. De Ferreira, A.C.; Nerini, F.F. A Framework for Implementing and Tracking Circular Economy in Cities: The Case of Porto. Sustainability 2019, 11, 1813. [CrossRef]

35. Alaerts, L.; Chapman, D.; Eyckmans, J.; Van Acker, K. Circular Economy Indicators for Person Mobility and Transport. 2020. Available online: https://lirias.kuleuven.be/3151407?limo=0 (accessed on 9 December 2020).

36. City of Amsterdam. Amsterdam Circular Monitor. 2020, p. 63. Available online: https: //www.amsterdam.nl/bestuur-organisatie/volg-beleid/coalitieakkoord-uitvoeringsagenda/gezondeduurzame-stad/amsterdam-circulair-2020-2025/ (accessed on 9 December 2020).

37. Christis, M.; Athanassiadis, A.; Vercalsteren, A. Implementation at a city level of circular economy strategies and climate change mitigation-The case of Brussels. J. Clean. Prod. 2019, 218, 511-520. [CrossRef]

38. Athanassiadis, A.; Christis, M.; Bouillard, P.; Vercalsteren, A.; Crawford, R.H.; Khan, A.Z. Comparing a territorial-based and a consumption-based approach to assess the local and global environmental performance of cities. J. Clean. Prod. 2018, 173, 112-123. [CrossRef]

39. Mertens, J.; Pauwels, H.; Van Couwenberghe, J. Leuven Circulair. 2020. Available online: https://roadmap. leuven2030.be/pdf/L2030_Roadmap_Programma9.pdf (accessed on 9 December 2020).

40. European Commission. Closing the Loop - An EU Action Plan for the Circular Economy; European Commission: Brussels, Belgium, 2015.

41. McKinsey \& Company. Growth Within: A Circular Economy Vision for a Competetive Europe. Study Commissioned by the Ellen MacArthur Foundation. Available online: https://www. ellenmacarthurfoundation.org/assets/downloads/publications/EllenMacArthurFoundation_GrowthWithin_July15.pdf (accessed on 9 December 2020).

42. Achterberg, E.; Hinfelaar, J.; Bocken, N. Master Circular Business with the Value Hil. 2016. Available online: https://publish.circle-economy.com/financing-circular-business (accessed on 5 December 2020).

43. Kenis, A.; Lievens, M. Imagining the carbon neutral city: The (post)politics of time and space. Environ. Plan. A Econ. Space 2016, 49, 1762-1778. [CrossRef]

44. Pop-Machina. Available online: https://pop-machina.eu/ (accessed on 5 December 2020).

45. Stad Leuven. Bestuursnota 2019-2025. 2019. Available online: https://www.leuven.be/sites/leuven.be/files/ documents/2019-10/baanbrekend_leuven_-_bestuursnota_2019-2025.pdf (accessed on 9 December 2020).

46. Freire, P. Pedagogie van de Onderdrukten (Translation of The Pedagogy of the Oppressed); De Toorn: Baarn, The Netherlands, 1972.

47. McNiff, J.; Whitehead, J. All You Need to Know about Action Research; Sage: London, UK, 2006.

48. Navare, K.; Muys, B.; Vrancken, K.C.; Van Acker, K. Circular economy monitoring-How to make it apt for biological cycles? Resour. Conserv. Recycl. 2020.

49. Cronon, W. Nature's Metropolis: Chicago and the Great West; Norton: New York, NY, USA, 1992.

50. Van Couwenberghe, J. Pop-Machina Verslag Workshop 'Naar een Materialenbank in Leuven' 2 December 2019; 2019; p. 15, Unpublished work.

51. Doménech, T.; Davies, M. The role of Embeddedness in Industrial Symbiosis Networks: Phases in the Evolution of Industrial Symbiosis Networks. Bus. Strat. Environ. 2010, 20, 281-296. [CrossRef]

52. UrbanWINS Toolkit. Available online: https://www.urbanwins.eu/toolkit/ (accessed on 5 December 2020).

53. SCREEN-lab. Assessment Criteria for Circular Economy Projects; Rev 4.0- March 2019. 2019. Available online: http://www.screen-lab.eu/deliverables/Table-rev4.pdf (accessed on 9 December 2020).

54. Taelman, S.; Sanjuan-Delmás, D.; Tonini, D.; Dewulf, J. An operational framework for sustainability assessment including local to global impacts: Focus on waste management systems. Resour. Conserv. Recycl. 2020, 162, 104964. [CrossRef]

55. Chapman, D.A.; Eyckmans, J.; Van Acker, K. Does Car-Sharing Reduce Car-Use? An Impact Evaluation of Car-Sharing in Flanders, Belgium. Sustainability 2020, 12, 8155. [CrossRef] 
56. Athanassiadis, A. Urban metabolism in policy and practice. In Urban Metabolism in Policy and Practice; Perspective.Brussels: Brussels, Belgium, 2019.

57. Weichselgartner, J.; Kasperson, R. Barriers in the science-policy-practice interface: Toward a knowledgeaction-system in global environmental change research. Glob. Environ. Chang. 2010, 20, 266-277. [CrossRef]

58. Perrotti, D. Evaluating urban metabolism assessment methods and knowledge transfer between scientists and practitioners: A combined framework for supporting practice-relevant research. Environ. Plan. B Urban Anal. City Sci. 2019, 46, 1458-1479. [CrossRef]

59. Boelens, L.; Dehaene, M.; Goethals, M.; Kuhk, A.; Schreurs, J. Living labs. Co-Evolutie Planning Met Onderzoekers, Overheden, Burgers en Ondernemers Voor Uitvoerbare Ruimtelijke Projecten 2015. Available online: https://biblio.ugent.be/publication/7022845/file/7022846.pdf (accessed on 9 December 2020).

Publisher's Note: MDPI stays neutral with regard to jurisdictional claims in published maps and institutional affiliations.

(C) 2020 by the authors. Licensee MDPI, Basel, Switzerland. This article is an open access article distributed under the terms and conditions of the Creative Commons Attribution (CC BY) license (http://creativecommons.org/licenses/by/4.0/). 